\title{
Multi-zone LVDC distribution systems architecture for facilitating low carbon technologies uptake
}

\author{
Abdullah Emhemed*, Dong Wang*, Graeme Burt*, Jawwad Zafar*, Ali Kazerooni†, Anthony \\ Donoghue:
}

*University of Strathclyde, Glasgow, UK, Abdullah.emhemed@strath.ac.uk, ${ }^{\dagger}$ WSP, UK, Ali.Kazerooni@wsp.com, ${ }^{\text {*SP Energy }}$ Networks, UK, adonoghue@spenergynetworks.co.uk

Keywords: Low Voltage Direct Current (LVDC), Low Carbon Technologies, DC protection and earthing

\begin{abstract}
Low voltage direct current (LVDC) distribution systems have recently been considered as an alternative approach to provide flexible infrastructure with enhanced controllability to facilitate the integration of low-carbon technologies (LCTs). To date, there is no business-as-usual example of LVDC for utility applications and only few trials have been developed so far. The deployment of LVDC in general will present revolutionary changes in LV distribution networks. This will require a rethinking of network design principles and the enablement of integrated solutions. This discussion paper reviews the current practice in utility-scale LVDC distribution networks worldwide. The paper also presents a new multizone architecture approach which can be used to better understand future of LVDC systems, and exploit their inherent flexibility to allow synergistic integration of multiple energy technologies.
\end{abstract}

\section{Introduction}

The anticipated growth in distributed low carbon technologies (LCTs) such as electric vehicles (EV), heat pumps, photovoltaic (PV), and electrical storage will put the infrastructure and operation of existing low voltage (LV) networks under significant pressure [1][2]. Electrification of more transport and heat will place increasing demand on LV networks. This can potentially overload MV/LV transformers and LV cables. As an example, the results of 'My Electric Avenue' project [1] have stated that $32 \%$ of the UK LV feeders (almost 312,000 circuits) will require 'intervention' when $40 \%-70 \%$ of customers have EVs with $3.5 \mathrm{~kW}$ power rating. Also, new technologies such as IEC61851 'Mode4' EV fast chargers with high power demand (i.e. $>50 \mathrm{~kW}$ ) require higher LV voltages and currents which cannot be supplied by traditional $0.4 \mathrm{kV}$ voltages [3]. Existing LV networks have also limited power management capability to cope with intermittent sources such as PVs. As an evidence, the results of monitoring transformers' utilisation of 200 secondary substations in the UK and as presented in [2] have demonstrated that $15 \%$ of the substations with photovoltaics (PVs) have some limited reverse power flow.
Implementing traditional reinforcement approaches to address the aforementioned challenges (e.g. building new substations and adding new cables) will be expensive, and interruptive. There are few new innovative solutions which have been implemented in LVAC networks to utilise any available spare power capacity to supply more customers. One example is the use of a power-electronic device as a 'soft open point' (SOP) to control power exchange between adjacent LV networks [4]. The SOP technology may not be applicable to the area that has LV networks with high penetration of EVs and with limited thermal loading capability. Another example to protect LV cables from potential overload when a large number of EVs are simultaneously connected is an active demand side management technique as presented in [1]. This technique, by shifting the demand away from peak times and control the voltage, has allowed additional $10 \%$ of customers to connect their EVs before LV voltages are saturated. It has also achieved $9 \%$ reduction in the cable losses.

To capitalise on these solutions and exploit the utilisation of existing assets such as LV cables, LV direct current (LVDC) distribution systems have the potential to provide a unique and flexible infrastructure to increase LV cables power transfer capacity, and reduce their associated thermal losses [5]-[8]. LVDC systems become more feasible due to the cost reduction of power electronics (continuous 5\% cost reduction in last two decades [9]), and the growing experience of DC protection. The AC-DC interface between LVDC and AC grids has the potential to enable new control functionalities which cannot be offered by conventional transformers. These include more effective voltage control, bidirectional power flow control, independent reactive and active power control, and fault level management capability.

To date, there is no utility in the world considering LVDC deployment as a business-as-usual. However, there is a number of examples of existing LVDC pilot projects worldwide and ongoing international standards development. These can provide useful learnings for taking LVDC technology to the next step. The challenge is that the majority of existing projects are driven by different needs and based on specific national solutions and standards. There is still no international standard on DC operating voltages, end-user interfaces, and protection arrangements. These have slowed the deployment and rollout of LVDC technologies. 
Therefore, this paper presents an overview of current practice in LVDC distribution networks for utility applications, and explores the potential benefits of such new technology in this sector. To handle the complexity that emerges from embedding LVDC technologies in existing AC grids, the paper also proposes a new concept of an LVDC multi-zone architecture approach. The approach helps better understanding of LVDC distribution systems layout, operation requirements, and potential LVDC future roadmaps. The focus of the paper is on LVDC for utility applications, and LVDC in buildings is out of the paper's scope.

\section{LVDC distribution networks for rural areas}

The key drivers for considering LVDC distribution networks in rural areas are the requirements for improving system reliability and security of supply [6]-[9]. For example and according to articles [9] and [10], the new Electricity Market Act in Finland (into force since 2013) has restricted the customer's power outages to be no more than 36 hours in rural areas by 2028. The Act also has tightened standard compensations to be paid by the Finnish distribution system operators (DSOs) to their customers for longer durations of power outages caused by extreme weather conditions [10]. LVDC distribution networks have been recognised by a number of DSOs in Finland as one of the remarkable technology that will help to meet these requirements. Currently, there are a number of LVDC distribution trials have been running in Finland to understand the potential benefits of replacing ageing MV circuits by $\pm 750 \mathrm{~V}$ LVDC in rural areas [7]-[10]. The research study presented in [11] has claimed that LVDC point-to-point solutions can approximately achieve $10-25 \%$ saving in life cycle costs compared to traditional reinforcement in AC in rural areas.

LVDC point-to-point example has also been implemented in a mountainous area in South Korea to reduce duration of power outages and minimise the overall maintenance cost [6]. The control capability of LVDC converters has enabled the integration of enhanced automation techniques. This has improved the system's overall response time, and significantly minimised the requirement of field crews work and power restoration time [6]. The research in [12] has also claimed that up to $5 \%$ saving in total operating cost could potentially be achieved in such kind of application.

LVDC role to improve the security of supply has also been recognised for utility-scale islanded systems. LVDC provides better infrastructure for managing local generation/loads to enable stable and optimal islanded operation. For example, the LVDC with a central BESS trial site reported in [13] can provide power for the relevant customers for 5 hours in the case of the main grid outages. The project detailed in [14] has also replaced an existing islanded AC microgrid by an LVDC microgrid to improve the management of the network. The decoupling provided by the DC infrastructure between the AC generators and loads can allow the generators to operate at their optimal speed with potential to reduce their mechanical losses, and improve their fuel efficiency and lifespan.

\section{LVDC distribution networks for urban areas}

For urban examples, the key drivers of LVDC deployment are reported to be the need for more power capacity in existing cables, and the provision of higher power availability through smarter real time energy management [15][16]. Compared to LVAC, only LVDC can control real power completely independent from reactive power. This will help distribution network operators (DNOs) to easily correct operational power factors, and apply effective voltage controls and power quality improvement. LVDC converters can act as a static synchronous compensator (STATCOM) to absorb/inject reactive power, and as a virtual plant to provide rapid power control to provide a wider system frequency support [8].

LVDC supply is also more suitable to connect DC fast chargers (IEC61851 Mode4 [3]) which are set to grow in future. In addition, DC street lighting with smart management have demonstrated energy savings of up to $70 \%$ in LVDC trials reported in [16]. The savings come from dimming the LED lights, and it can be argued that this can be achieved with LVAC as well. But using DC for supplying smart LED street lightings will eliminate the usage of electrolytic capacitors in the LED drivers, resulting in significant improvement in the drivers' reliability and lifetime [16].

\section{Discussion on LVDC technical requirements}

The lack of standards and limited experience, the need for novel power-electronic architectures with reduced losses and cost, and advanced DC protection have been identified as the major issues facing the implementation of LVDC in utilities [5]-[13]. This section discusses these issues as follows.

\subsection{Selection of $L V D C$ operating voltages}

Due to the lack of standards on LVDC voltages, there is no consensus on one LVDC voltage yet. The EU LV Directive (LVD) $2006 / 95 / E C$ has identified $1500 \mathrm{~V}$ as the maximum voltage to be considered as an LVDC [17]. The IEC60038 and IEC61140 have divided the LV in DC systems into two bands [18][19]. From 120V-1500V is defined as an LVDC band and $\angle 120 \mathrm{~V}$ is an Extra LVDC (ELVDC) band. ELVDC band $<120 \mathrm{Vdc}$ is more suitable for supplying majority of electronic loads within DC building installations.

LVDC with voltages $>120 \mathrm{~V}$ and $<400 \mathrm{~V}$ is more appropriate to supply medium load sizes $0.5-20 \mathrm{~kW}$, including EV with on-board charger $<7.5 \mathrm{~kW}$ and land-based charger $<20 \mathrm{~kW}$. Pure resistive loads run on RMS 230Vac can be supplied directly by $230 \mathrm{Vdc}$. Also, minimum modification will be required for devices with input rectifiers that give the peak of $230 \mathrm{Vac}$ (i.e. $326 \mathrm{Vdc}$ ). The only existing worldwide LVDC voltage standard to operate in this range is the EMerge Alliance $380 \mathrm{Vdc}( \pm 190 \mathrm{Vdc})$ [20]. This was originally developed for DC data centres, and has been adopted in a number of DC microgrids [14]. $\pm 190 \mathrm{Vdc}$ systems will always operate within the safety DC-1 and DC-2 zones as shown in Figure 1. 20mA-80mA DC-RCDs can be used to protect against direct contact faults in such systems. 


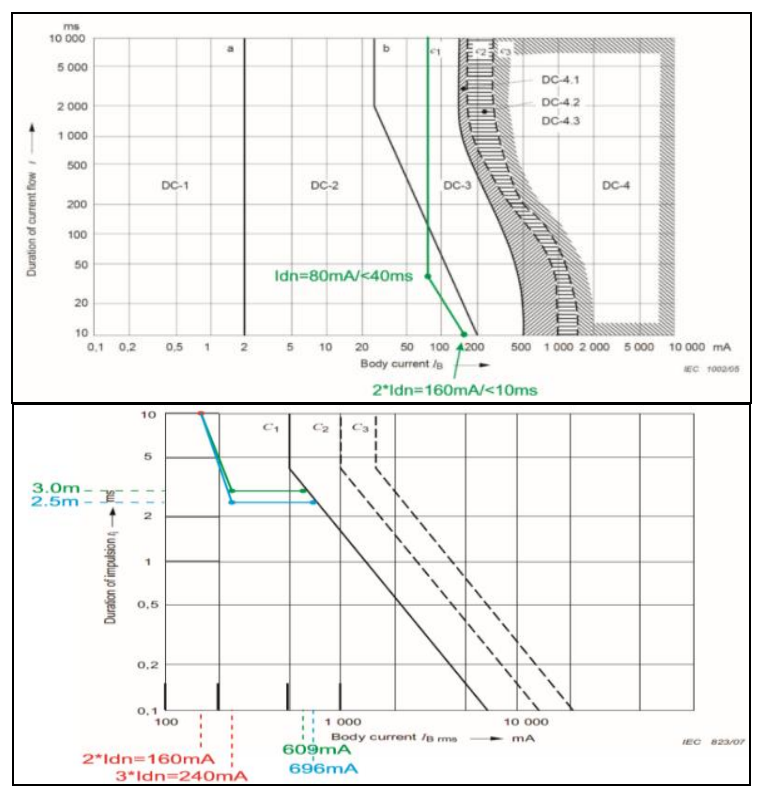

Figure 1: Time/current zones of effects of DC currents on persons: (top) $>10 \mathrm{~ms}$, and (bottom) <10ms [21]

From the safety perspective, $380 \mathrm{Vdc}$ touch voltage will

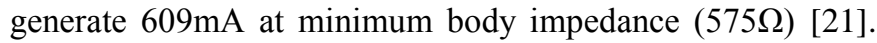
As shown in Figure 1, the maximum non-hazardous time period against this current is $3 \mathrm{~ms}$. According to the IEC60479-1 to protect against DC up to $400 \mathrm{Vdc}$, DC-RCD with a rated residual operating current $(\mathrm{I} \Delta \mathrm{n})=<80 \mathrm{~mA}$ has to operate within $2.5 \mathrm{~ms}$ at $(3 \mathrm{I} \Delta \mathrm{n}=240 \mathrm{~mA})$.

For large power loads $>20 \mathrm{~kW}$, LVDC with voltages $>400 \mathrm{Vdc}$ is recommended to minimise LV cable thermal losses and the requirement for large size cables. According to the IEC61851, up to $500 \mathrm{Vdc}$ supply is required for EV fast charger $>50 \mathrm{~kW}$. Also, 3-phase 400Vac loads with input rectifiers will require minimum/zero modification when they are supplied by $560 \mathrm{Vdc}$. In the LVDC trials reported in [16], three different voltage levels are used for supplying large LV loads. These include $\pm 350 \mathrm{Vdc}$ with $\pm 30 \mathrm{Vdc}$ droop band, $700 \mathrm{Vdc}$ with $\pm 60 \mathrm{Vdc}$ droop band, and $\pm 700 \mathrm{Vdc}$ with $\pm 60 \mathrm{Vdc}$ droop band.

\subsection{Cable configurations and labelling}

The two common LVDC cable configurations are 2-wire (unipolar) systems and 3-wire (bi-polar) systems. The IEC $60364-$ 1 has identified the marking of positive pole as L+, the negative pole as L-, and the mid-point as M [23]. But, there is still no international agreement on the labelling and colour coding of DC cables. For new installations, LVDC cable colours red for $\mathrm{L}+$, black for $\mathrm{L}-$, and blue for $\mathrm{M}$ conductor are used in Netherlands [16]. To avoid any possible confusion between DC and AC when existing AC cables are used for DC, the IET BS7671 has provided a guidance on DC cable colours (see Table 1). Different colour selection is proposed by the LVDC trial in [7] when AC cables are used for DC.

\subsection{DC protection challenges}

The deployment of power electronics in LVDC will introduce new forms of faults which will fundamentally change LV protection and earthing requirements. Power-electronic converters have relatively limited capability to withstand short circuits. With suitable configuration, the converters have the ability to completely block the main grid fault currents for the purpose of self-protection, resulting in protection coordination challenges with downstream protection. Also, power-electronic converters are sensitive to the rapid depression of DC voltages caused by short circuits. This can potentially make the converters lose control and more likely to trip before downstream protection, leading to substandard selectivity and unnecessary trip. In addition, Power electronics introduce high frequency components and common-mode noise which require special earthing arrangement to minimise the impact of these issues.

\begin{tabular}{|c|c|c|c|c|}
\hline \multirow[t]{2}{*}{ Function } & \multirow[t]{2}{*}{ Marking } & \multicolumn{3}{|c|}{ Colour } \\
\hline & & IET BS7671 & Finland & $\begin{array}{l}\text { Netherlands } \\
\text { new installation }\end{array}$ \\
\hline $\begin{array}{l}\text { Positive of } \\
\text { three-wire } \\
\text { circuit }\end{array}$ & L+ & & & \\
\hline $\begin{array}{l}\text { Mid-wire } \\
\text { of three- } \\
\text { wire circuit }\end{array}$ & M & & & \\
\hline $\begin{array}{l}\text { Negative } \\
\text { of three- } \\
\text { wire circuit }\end{array}$ & L- & & & \\
\hline
\end{tabular}

Table 1: DC conductor marking and colours selection using existing AC wires [22]

\section{4. $L V D C$ earthing requirements}

Similar to AC systems, the IEC60364-1 has identified five different types of DC system earthing arrangements, including TN-S, TN-C, TN-C-S, TT, and IT [23]. Out of these five, IT (see Figure 2) and TN-S (see Figure 3) earthing configurations are recommended for LVDC networks [13], [16]. IT earthing has been implemented in existing LVDC trials with DC voltages $>400 \mathrm{Vdc}$ as reported in [6] and [13]. In these projects isolation monitoring devices (IMD) are used to provide protection against earth fault which can be an issue in IT systems. On the customer side, galvanic isolation transformers are used within the converters interface to decouple the supply and the loads and avoid the provision of extreme dangerous contact voltages (i.e. $>400 \mathrm{Vdc}$ ) to the customer. The IT floating LVDC cables will also minimise the noise currents generated by the switching mode of the LVDC converters in the AC due the absence of shared PE.

For LVDC systems with operating voltages $<400 \mathrm{Vdc}$, TN earthing can be used. If such supply voltage will be provided directly to the customer, DC-RCDs with residual operating current $(\mathrm{I} \Delta \mathrm{n})=<80 \mathrm{~mA}$ which can operate within $2.5 \mathrm{~ms}$ for the $(3 \mathrm{I} \Delta \mathrm{n}=240 \mathrm{~mA})$ at $400 \mathrm{Vdc}$ is needed [21]. For voltages $<200 \mathrm{Vdc}$, the $80 \mathrm{~mA}$ DC-RCDs have to operate within maximum operating time $<0.4 \mathrm{~s}$ [21]. Galvanic isolation might still be required for common-mode noise reduction.

In addition, it is also important when an LVDC network is earthed as a TN to consider the avoidance of corrosions of any metal surfaces connected to the DC PE. This is similar requirement as stated by BS7430 for traction systems used in UK with 600-750V DC [24]. In response to this, LVDC 
systems can be earthed using diodes as in traction systems or through capacitive grounding [17], or by using a diode with a capacitor in parallel as shown in Figure 4. With such earthing, no DC current leakage through the protective earth conductor during the normal operation will be noticed. The flow of the current is allowed only under earth fault conditions. In this case, LVDC can only be configured as a TN-S.
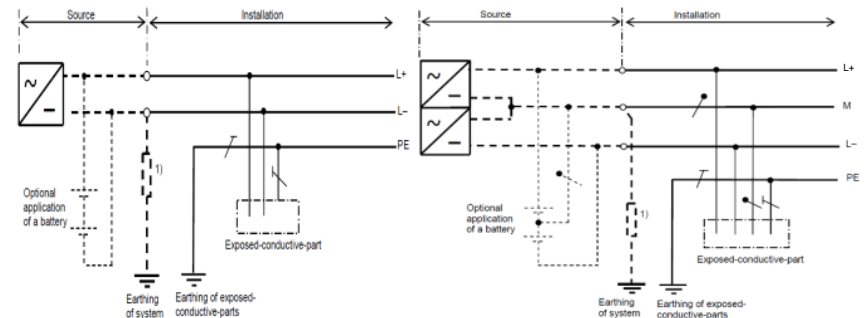

Figure 2: IT DC system earthing configuration (left) 2-wire system, and (right) 3-wire [23]
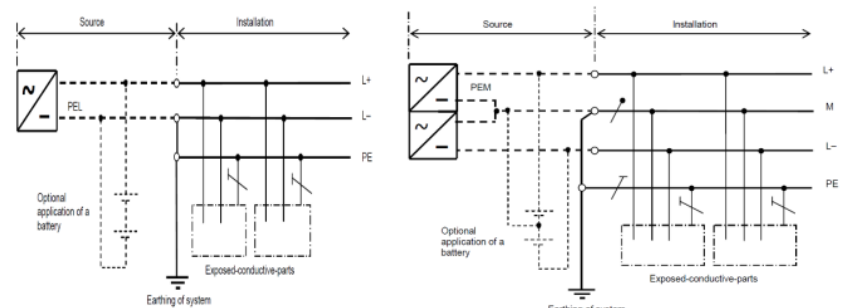

Figure 3: TN-S DC system earthing configuration (left) 2wire system, and (right) 3-wire [23]
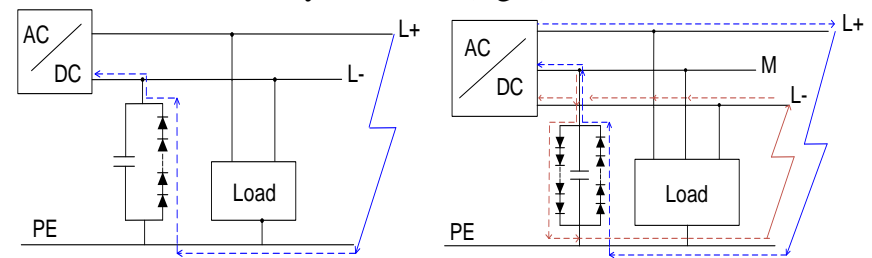

Figure 4: Capacitive and diodes earthing of DC system (left) 2-wire system and (right) 3-wire system

\subsection{Power quality and EMC compatibility}

To date, there are no standards defining electromagnetic interference (EMI) compatibility requirements for DC systems in the range of $2-150 \mathrm{kHz}$. It has been stated in [7] that IEC62578:2015 provides the design recommendations for the interference emission of active converters below $150 \mathrm{kHz}$ [27], but no clear EMI limits are defined for DC systems. Recently, a new IEC Technical Committee Working Group (TC8/WG9) (started in May 2018) has been set up to conduct a preliminary work on DC voltages and power quality requirements for LVDC, and will provide recommendations for future standards development [28].

\section{LVDC multi-zone architecture concept}

Existing LVAC distribution networks have been designed to operate on one regulated voltage with same cable configurations, and are protected by overcurrent protection. The deployment of LVDC will radically change such a 'unified regime' to a 'multi regime' in terms of operating voltage, earthing and protection requirements, and interfaces between different voltage levels.
This section presents a new concept of a multi-zone architecture approach which can be used to better understand future LVDC system structures embedded within AC networks. Figure 5 presents the layout of embedded LVDC distribution system in an AC distribution grid with multiple zones. Based on the voltage levels required to supply different load sizes, the LVDC system is divided into three zones shown as Zone 1-3 in Figure 5, in addition to one AC zone shown as Zone 4. Each zone is described as follows.

Zone 1 encompasses the highest DC voltages $> \pm 400 \mathrm{~V}$ and $< \pm 750 \mathrm{~V}$ to exploit power capacity in full. Zone 1 provides a high power capacity corridor to supply large loads such as $50 \mathrm{~kW}-350 \mathrm{~kW}$ fast chargers, and enables longer power transmission distances. The voltage levels within this zone are outside the safety limits that have been identified by the IEC60479 [21]. Thus, the customers' load cannot be connected directly to Zone 1, and galvanic isolation (see Figure 5) is required. Zone 1 has to be configured as an IT earthed system, and it can be identified as a floating Zone.

Zone 2 covers the voltages $\pm 320 \mathrm{Vdc}- \pm 380 \mathrm{Vdc}$, and provides lower power capacity than Zone 1 . It is also still possible to supply large loads such as EVs DC fast chargers through pole-to-pole outputs. But, larger cable sizes and higher losses could be experienced in comparison to Zone 1 . Zone 2 voltages are within the IEC60479 safety margins if electronicbased DC-RCDs to provide $3 \mathrm{~ms}$ operation are used [23]. But, the zone has to be designed as a TN-S to provide protection for safety and minimise the risk of corrosion issues.

Zone 3 includes voltages $< \pm 200 \mathrm{Vdc}$. This voltage range is suitable for supplying most of the loads that can be supplied by today's LVAC distribution (i.e. $230 \mathrm{~V}$ ). The $\pm 200 \mathrm{Vdc}$ has the same safety margins as for existing LV AC installations as identified by the IEC60479. Mechanical based DC-RCDs with residual operating current $80 \mathrm{~mA}$ are possible to be use to provide personnel safety within this zone. Zone 3 also needs to be configured as a TN-S system to provide protection for safety and minimise the risk of corrosion issues.

Zone 4 presents conventional LVAC networks where all the safety requirements are based on existing well-known standards and wiring regulations. Within this $\mathrm{AC}$ zone the fault current levels are normally high and the earthing arrangements are based on TN systems (TN-C-S or TN-S).

The multi-zone architecture approach will facilitate the identification of different operational requirements for each zone. This will help to make the appropriate studies, testing, and integration of appropriate solutions according to each zone's characteristics. Key parameters that characterise each zone include:

- Operating voltage levels and associated voltage droop bands for active zones

- Power capacity and ratings

- Zone-to-zone power-electronic interfaces and scalability (these can include smart electronic transformer, AC-DC (or DC-AC) converters, and DC-DC converters). 


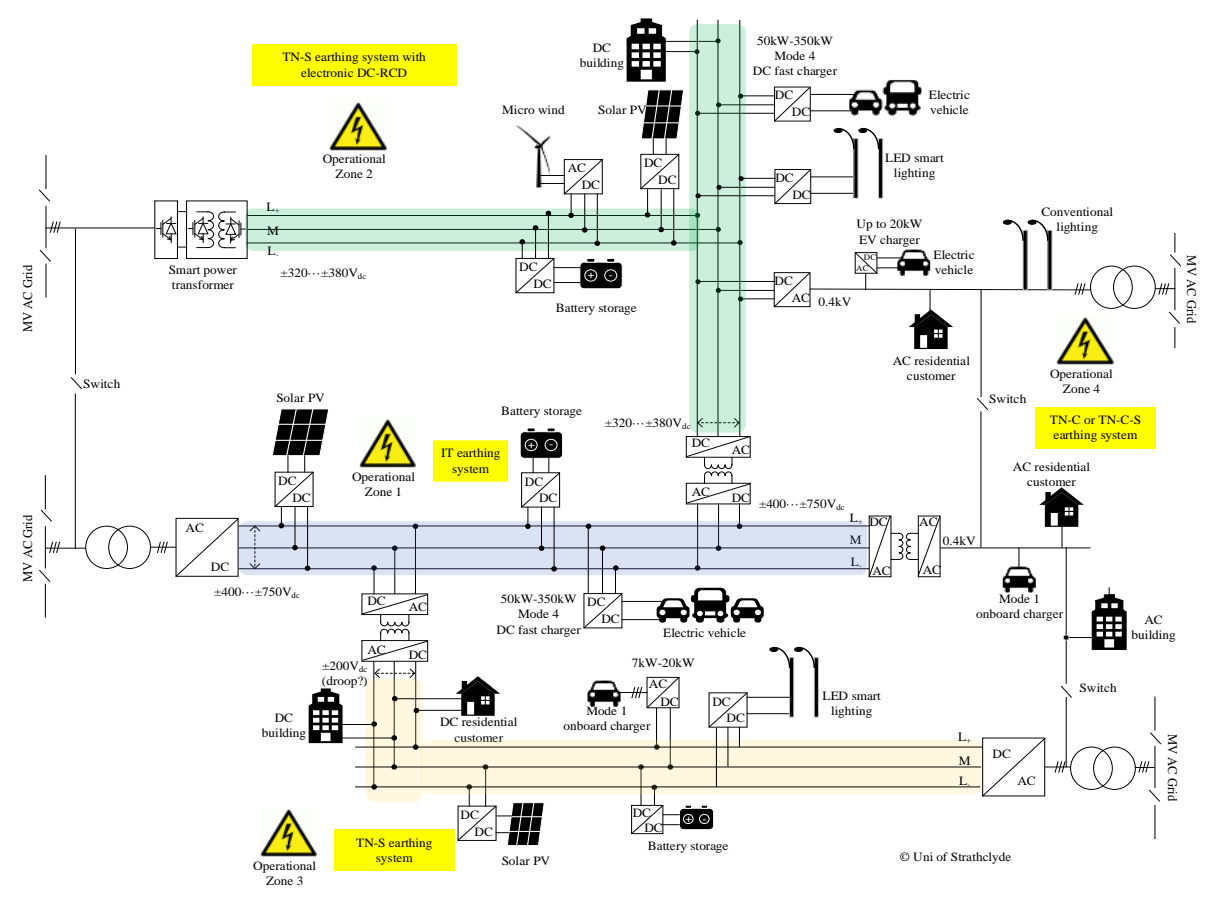

Figure 5: Embedded LVDC distribution system with multi-zone architecture

- Earthing arrangements and requirements

- Cable configurations and sizes

- Protection requirements (influenced by the powerelectronic interfaces between the zones)

- Control requirements (e.g. in association to power sharing, energy management, voltage controls, wider system support, payment model, and etc.)

The technical characteristics of each zone can also have an impact on the cable choices. Due to the use of different power-electronic interfaces to provide different DC voltages and different current controls, not all the used LV cables will experience the same current in each zone. Consequently, different size of cables can be deployed in accordance to the associated zone characteristics. If existing LVAC cables are intended to be used for LVDC applications, they can be tested and characterised in accordance to each zone's technical requirements.

At network level and for specific use cases such as rural networks with long feeders and urban areas with high power density, Zone 1 is the most suitable choice. As the Zone 1 supply terminals approach the customers, Zone 1 can be converted to Zone 2 or Zone 3 through a DC-DC converter(s) with galvanic isolation transformer(s) or to Zone 4 through a DC-AC converter(s). Whilst, Zone 2 is more appropriate example for urban applications when improved system controllability and enhanced energy management is required and has more value than increased power capacity in terms of installation and operation costs. Zone 3 is more favourable for lower loads such as small buildings, street lightings, commercial offices, and etc.

From market perspective, each zone has different drivers. With today's digital era (DC electronic devices dominate more than AC loads in buildings) and due to the growth of transport and heat demand in future distribution networks, LVDC technologies are likely to be developed through both bottom-up (Zone 3 to Zone 1) and top-down (Zone 1 to Zone 3) approaches. For example, the study reported in [29] has concluded that DC for commercial buildings will "grow from \$320 million in annual revenue in 2013 to more than \$2.8 billion in 2020". Such growth may stimulate customers to install more DC distributions within their premises, and potentially motivate utilities to provide DC supplies for the customers. On the other hand, existing LVDC trials as discussed previously in the paper have demonstrated that using LVDC point-to-point has great potential to increase LV networks power transfer capacity. Therefore, Zone 1 could also be installed as an LVDC link without any changes on the customer side. In this case, Zone 3 and Zone 1 could potentially converge to form Zone 2 , leading to a system with multiple operation zones.

\section{Conclusions}

The paper has reviewed a number of existing LVDC distribution network projects directly related to utility-scale applications, and outlined the key benefits and challenges of LVDC in this sector. Replacing existing MV/LV AC networks by LVDC networks has demonstrated the benefits of minimising power outages and restoration times in rural networks due to the intelligent functionalities provided by power-electronic converters. For urban examples, existing trials have demonstrated workable LVDC systems with enhanced controllability. But none of existing trials has tested in practice the realisation of increased power flow capacity when AC cables are energised by DC with higher voltages. There are still key outstanding barriers stemming from the lack of experience and complexity of designing and 
protecting LVDC. The paper has introduced a multi-zone architecture concept which has simplified such complexity by facilitating better understanding of LVDC layouts. This is in addition to identification of clear boundaries between different LVDC operational zones, and outlining their associated technical requirements in terms of voltage ranges and earthing configurations.

To achieve the perceived value offered by LVDC systems, it is important to accelerate the development of new relevant standards and grid codes that fit well within the LVDC technology requirements. Designing LVDC solutions based on legacy LVAC principles due to the lack of appropriate standards and regulations will limit the opportunity to realise optimal system performance, and may increase the cost of implementing future low-carbon energy technologies. Consequently, a determined approach to conduct relevant testing, while identifying and implementing more innovative LVDC solutions, using the latest available technologies is significantly important at this stage of LVDC development to modernise our future distribution networks.

\section{Acknowledgements}

This research work was supported by the SP Energy Networks as a part of the Network Innovation Allowance (NIA) 'transition to LVDC distribution networks' phase1 project.

\section{References}

[1] SSEN, "My Electric Avenue" project, http://myelectricavenue.info/learning-outcomesA

[2] ENW, "Low Voltage Network Solutions", closedown report, Jun. 2014, available at: https://www.ofgem.gov.uk/system/files/docs/2017/04/lv ns_closedown_report.pdf

[3] IEC61851-1:2011, Electric vehicle conductive charging system-Part 1: General requirements

[4] W. Cao, et al., "Operating principle of Soft Open Points for electrical distribution network operation," Applied Energy, Vol. 164, pp. 245-257, Feb. 2016.

[5] A. Emhemed, et al., "Validation of fast and selective protection scheme for an LVDC distribution network," IEEE Trans. Power Deliv., vol. 32, no. 3, pp. 1-1, 2017.

[6] Y. Cho, et al., "Construction of actual LVDC distribution line," CIRED2017, Jun. 2017.

[7] T. Kaipia, et al., "LVDC rules - technical specifications for public LVDC distribution network," CIRED2017, Jun. 2017

[8] Ensto Oy, "Economical benefits and higher quality with LVDC Microgrid2, published on 2nd Feb. 2018, and available https://www.ensto.com/company/newsroom/articles

[9] T. Hakala, et al., "LVDC pilot implementation in public distribution network," In Proc. CIRED2015, Jun. 2015.

[10] T. Hakala, "Prioritization Principles for the Reinvestment Plan of Low Loaded Parts of the Rural Medium Voltage Network, MSc thesis, Nov 2013.
[11] T. Kaipia, et al., "Comparison of LVDC distribution network alternatives: full-DC vs link-type solutions," CIRED2017, Jun. 2017.

[12] D. Afamefuna, et al., "A techno-economic feasibility analysis on LVDC distribution system for rural electrification in South Korea," Journal of Electrical Engineering \& Technology, vol. 9, pp. 742-751, Apr. 2014.

[13] P. Nuutinen, "Power Electronic Converters in Low Voltage Direct Current Distribution - analysis and implementation", $\mathrm{PhD}$ thesis, Lappeenranta University of Technology, Dec. 2015.

[14] H. Kim, et al., "Demonstration of LVDC distribution system in island," CIRED2017, Jun. 2017.

[15] A. Emhemed, et al., "An Advanced Protection Scheme for Enabling an LVDC Last Mile Distribution Network", IEEE Trans. Smart Grid, vol. 5, no. 5, pp. 2602-2609, Sep. 2014.

[16] Direct Current BV, https://www.directcurrent.eu/en/

[17] Low Voltage Directive (LVD), EU LV Legislation LVD2006/95/EC, Dec. 2006.

[18] IEC60038:2009, IEC standard voltages

[19] IEC61140:2016, Protection against electric shockCommon aspects for installation and equipment.

[20] The EMerge Alliance Data/Telecom Centre Standard, available at: https://www.emergealliance.org

[21] IEC60479-5:2007, Effects of current on human beings and livestock-Part 5: Touch voltage threshold values for physiological effects

[22] IET, 17th Edition Wiring Regulations, Table 7E/Appendix 7, 2015.

[23] IEC60364-1:2005: Low-voltage electrical installations.

[24] BS 7430:2011, "Code of practice for protective earthing of electrical installations", British Standards Institution, Aug. 2015

[25] D. Paul, "DC Traction Power System Grounding", IEEE Transactions on Indus. Applications, vol. 38, no. 3, pp. 818-824, May/Jun. 2002

[26] L. Mackay, et al., "Capacitive grounding for DC distribution grids with two grounding points", IEEE Second International Conference on DC Microgrids (ICDCM2017), pp. 76-80, 27-29 Jun. 2017.

[27] IEC/TS 62578:2015, Power Electronics Systems and Equipment-Operation Conditions and Characteristics of Active Infeed Converter (AIC) Applications Including Design Recommendations for Their Emission Values Below $150 \mathrm{kHz}$, technical specification.

[28] IEC TC8 A Preliminary Work item (PWI) (TR 8-2 ED1) on "Assessment of standard voltages and Power Quality requirements for LVDC distribution", http://www.iec.ch/dyn/www/f?p=103:23:102165872789

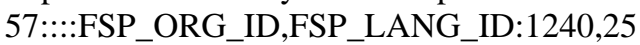

[29] Press release (20 Feb. 2014), "Direct Current Power Supply Equipment for Commercial Buildings Will Reach \$2.8 Billion in Annual Revenue by 2020," Navigant Research available: http://www.navigantresearch.com/newsroom/ 